\title{
Multihull vessel excitations in stochastic formulation
}

Agnieszka Królicka, M. Sc.

Gdansk University of Technology

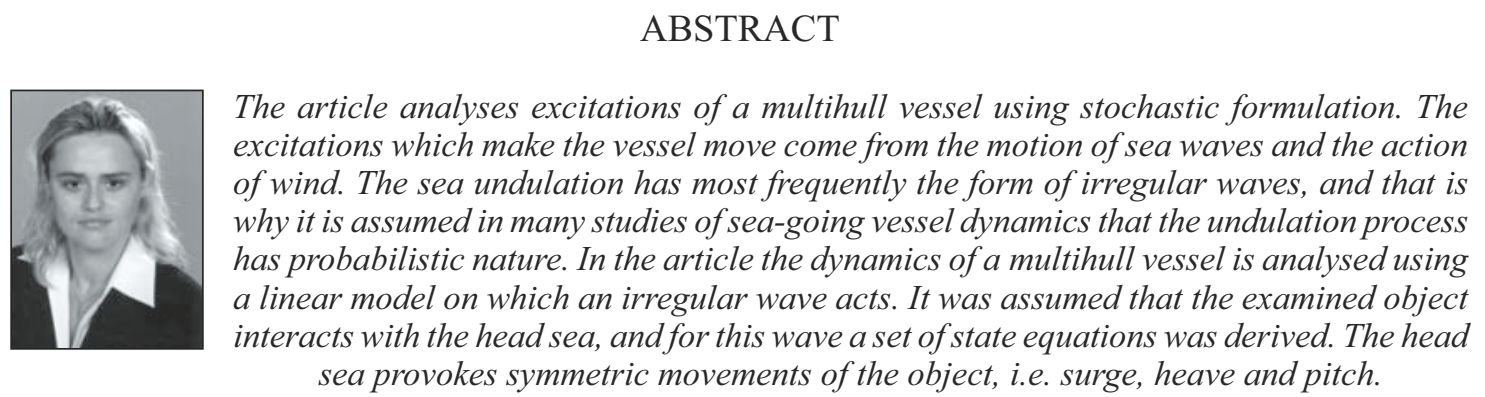

Keywords: excitations, multihull vessel, stochastic formulation, the motion of sea waves, vessel

\section{INTRODUCTION}

The motion of a vessel is mainly provoked by the excitations coming from sea waves. The nature of the wind undulation, along with difficulties in determining precisely the initial conditions for the motion of sea waves, are the reasons why the dynamics of the sea waves can be only modelled within the framework of the stochastic theory [6,7]. The basic quantity in the stochastic theory of sea motion is the function $\eta(x, y, t)$ which characterises the altitude of the sea surface with respect to the undisturbed reference state. The function $\eta(x, y, t)$ is a random function of time and position [1]. Probabilistic properties of this function are partially derived based on the results of measurements and partially from the hydrodynamic theory of waves. It is usually assumed in dynamic analyses that the process of sea undulation is stationary, ergodic, and Gaussian [8]. These assumptions facilitate developing mathematical models, and their effect can be assessed via identification and estimation. At those assumptions, the process $\eta(x, y, t)$ is characterised for an arbitrary fixed point $(x, y)$ by the spectral density $g_{n}(\omega)$. Having known the spectral density of the Gaussian random function $\eta(x, y, t)$, for instance, we can find the wave time scale $T_{s}$ and height $h_{s}$. The time scale is defined as the average time between successive instants at which the average calm sea level is exceeded, while the wave height represents the expected value equal to one third of the highest wave height.

The dynamic model comprises a deterministically defined non-deformable object which is subject to the action of a wave, the state of which is described in stochastic formulation. The forces which act on the multihull vessel come from irregular waves.

\section{WAVE-EXCITED MULTIHULL VESSEL MOVEMENTS}

For the vessel treated as a rigid object moving at constant speed $\mathrm{v}$ and arbitrary angle with respect to the direction of sea waves, its movements can be described by the mathematical model having the form a set of second-order differential equations (1). Local movements of the object around its equilibrium position are its response to the excitations coming from sea undulation.

If the model of the dynamic system is a linear model of a vessel, then the equations [5]:

$$
\sum_{i, j=1}^{6} I_{i j} \eta_{i}+B_{i j} \eta_{i}+C_{i j} \eta_{i}=F_{i}(t)
$$

where:

$\mathrm{I}=\mathrm{M}+\mathrm{A}-$ inertia matrix

M - elements of generalised mass matrix for the construction

A $\quad-$ elements of hydrodynamic mass- added mass matrix

B $\quad-$ hydrodynamic damping matrix

C $\quad-$ hydrostatic stiffness matrix

$\eta \quad-$ generalised displacement vector

$\mathrm{F}(\mathrm{t}) \quad-$ vector of exciting forces and moments,

can be analysed as a set of two uncoupled groups of mutually coupled equations. We assume the existence of the coupling via linear and nonlinear damping coefficients and hydrostatic elasticity coefficients.

In our analyses the examined object is idealised as the linear dynamic system with six degrees of freedom, which are: 
$\rightarrow$ longitudinal oscillation (surge) $-\eta_{1}$

$\rightarrow$ transverse oscillation (sway) $-\eta_{2}$

? heaving $-\eta_{3}$

rolling $-\eta_{4}$

$\rightarrow$ pitching $-\eta_{5}$

yawing $-\eta_{6}$

The coordinate system fixed to the catamaran is shown in Fig. 1.

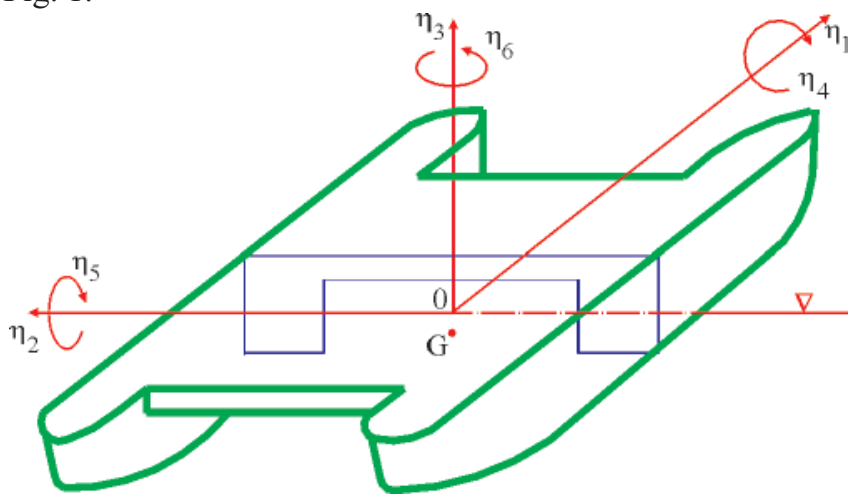

Fig. 1. Scheme of the physical model of the catamaran

The first group of equations comprises symmetric (longitudinal) movements, which include: $\eta_{1}$ - linear longitudinal moments (surging), $\eta_{3}$ - linear vertical movements (heave) and $\eta_{5}$-angular longitudinal movements (pitch).

The second group comprises the equations which describe antisymmetric (transverse) movements, including: $\eta_{2}$ - transverse linear movements (swaying), $\eta_{4}$ - transverse angular movements (rolling), and $\eta_{6}$ - horizontal angular movements (yawing).

In our final discussion we will neglect $\eta_{1}$ - linear longitudinal movements (surging), which are usually analysed using models with one degree of freedom. Consequently, in our case the mathematical model consists of 5 differential equations.

Our goal is to derive stochastic differential equations. Therefore in order to simplify the division of movements, let us introduce new variables given by the relation (2):

$$
\left\{\begin{array}{l}
\eta_{1} \\
\eta_{3} \\
\eta_{5} \\
\eta_{2} \\
\eta_{4} \\
\eta_{6}
\end{array}\right\}=\left\{\begin{array}{l}
z_{1} \\
z_{2} \\
z_{3} \\
z_{4} \\
z_{5} \\
z_{6}
\end{array}\right\}
$$

For the symmetric and antisymmetric movements selected by us the developed set of differential equations (1) takes the form:

$$
\begin{gathered}
\left\{\begin{array}{l}
\left(\mathrm{M}_{33}+\mathrm{A}_{33}\right) \ddot{z}_{2}+\left(\mathrm{M}_{35}+\mathrm{A}_{35}\right) \ddot{\mathrm{z}}_{3}+\mathrm{B}_{33} \dot{\mathrm{z}}_{2}+\mathrm{B}_{35} \dot{\mathrm{z}}_{3}+\mathrm{C}_{33} \mathrm{z}_{2}+\mathrm{C}_{35} \mathrm{z}_{3}=\mathrm{F}_{3} \\
\left(\mathrm{M}_{23}+\mathrm{A}_{23}\right) \ddot{z}_{2}+\left(\mathrm{M}_{25}+\mathrm{A}_{25}\right) \ddot{\mathrm{z}}_{3}+\mathrm{B}_{23} \dot{\mathrm{z}}_{2}+\mathrm{B}_{25} \dot{\mathrm{z}}_{3}+\mathrm{C}_{23} \mathrm{z}_{2}+\mathrm{C}_{25} \mathrm{z}_{3}=\mathrm{F}_{2}
\end{array}\right. \\
\left\{\begin{array}{l}
\left(\mathrm{M}_{42}+\mathrm{A}_{42}\right) \ddot{\mathrm{z}}_{4}+\left(\mathrm{M}_{44}+\mathrm{A}_{44}\right) \ddot{\mathrm{z}}_{5}+\left(\mathrm{M}_{46}+\mathrm{A}_{46}\right) \ddot{\mathrm{z}}_{6}+\mathrm{B}_{42} \dot{\mathrm{z}}_{4}+\mathrm{B}_{44} \dot{\mathrm{z}}_{5}+\mathrm{B}_{46} \dot{\mathrm{z}}_{6}+\mathrm{C}_{42} \mathrm{z}_{4}+\mathrm{C}_{44} \mathrm{z}_{5}+\mathrm{C}_{46} \mathrm{z}_{6}=\mathrm{F}_{4} \\
\left(\mathrm{M}_{52}+\mathrm{A}_{52}\right) \ddot{\mathrm{z}}_{4}+\left(\mathrm{M}_{54}+\mathrm{A}_{54}\right) \ddot{z}_{5}+\left(\mathrm{M}_{56}+\mathrm{A}_{56}\right) \ddot{\mathrm{z}}_{6}+\mathrm{B}_{52} \dot{\mathrm{z}}_{4}+\mathrm{B}_{54} \dot{\mathrm{z}}_{5}+\mathrm{B}_{56} \dot{\mathrm{z}}_{6}+\mathrm{C}_{52} \mathrm{z}_{4}+\mathrm{C}_{54} \mathrm{z}_{5}+\mathrm{C}_{56} \mathrm{z}_{6}=\mathrm{F}_{5} \\
\left(\mathrm{M}_{62}+\mathrm{A}_{62}\right) \ddot{\mathrm{z}}_{4}+\left(\mathrm{M}_{64}+\mathrm{A}_{64}\right) \ddot{\mathrm{z}}_{5}+\left(\mathrm{M}_{66}+\mathrm{A}_{66}\right) \ddot{\mathrm{z}}_{6}+\mathrm{B}_{62} \dot{\mathrm{z}}_{4}+\mathrm{B}_{64} \dot{\mathrm{z}}_{5}+\mathrm{B}_{66} \dot{\mathrm{z}}_{6}+\mathrm{C}_{62} \mathrm{z}_{4}+\mathrm{C}_{64} \mathrm{z}_{5}+\mathrm{C}_{66} \mathrm{z}_{6}=\mathrm{F}_{6}
\end{array}\right.
\end{gathered}
$$

Having solved this set of equations we get the solutions for acceleration coordinates $\ddot{z}_{2}$ and $\ddot{z}_{3}$ for symmetric movements, and $\ddot{z}_{4}, \ddot{z}_{5}, \ddot{z}_{6}$ for antisymmetric movements (see the scheme shown in Fig. 2).

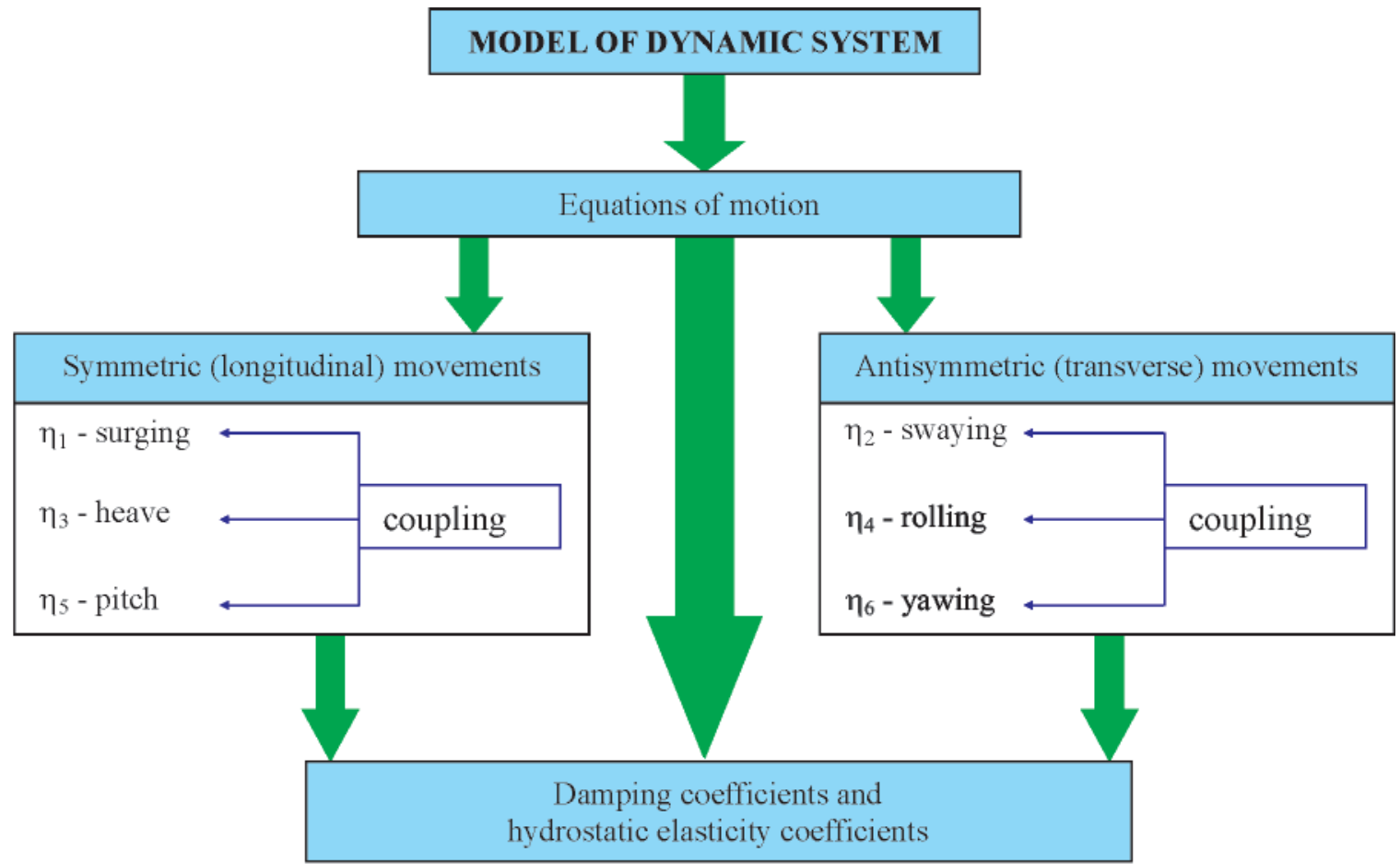

Fig. 2. Schematic division of multihull vessel motion equations in the linear model of the dynamic system 
Constructional aspects (symmetry) of multihull vessels make it possible to analyse group-coupled movements of the vessel, thus reducing the number of state variables in the equations.

\section{EXTERNAL RANDOM EXCITATIONS}

\section{Exciting forces}

Fig. 3 shows a sequence of actions aiming at the assessment of the generalised exciting forces.

The exciting forces come from the water undulation and the diffraction of waves, consequently they can be presented as functions of the wave velocity potential $\varphi_{\mathrm{W}}$ and the diffraction potential $\varphi_{\mathrm{D}}[10]$ :

$$
\overrightarrow{\mathrm{F}}_{\mathrm{m}}=-\mathrm{i} \rho \omega \int_{\mathrm{S}} \overrightarrow{\mathrm{n}}_{\mathrm{m}}\left(\phi_{\mathrm{W}}+\phi_{\mathrm{D}}\right) \mathrm{dS}
$$

where:

$\overrightarrow{\mathrm{F}}_{\mathrm{m}}$ for $\mathrm{m}=1,2,3 \quad-$ orthogonal projections of the external $\vec{F}_{\mathrm{m}}$ for $\mathrm{m}=4,5,6 \quad-\quad \begin{aligned} & \text { forces } \\ & \text { orthogonal projections of the vector of }\end{aligned}$ moments of the external forces

$\mathrm{S} \quad-$ catamaran's wetted surface

$\overrightarrow{\mathrm{n}}_{\mathrm{m}} \quad-$ unit vectors in the direction perpendicular to surface $\mathrm{S}$ for $\mathrm{m}=1,2,3,4,5,6$.

The process $F(t)$ in the equation (1) can be presented as a multidimensional homogeneous Markov process which corresponds to the vector $\mathrm{Y}\left(\mathrm{y}_{1}, \mathrm{y}_{2}, \ldots \mathrm{y}_{\mathrm{n}}\right)$ in the phase space, where $\mathrm{Y}=\mathrm{F}(\mathrm{t})$.

If we assume that the excitation $F(t)$ has the form

$$
\mathrm{F}(\mathrm{t})=\sum_{0}^{3}\left(\mathrm{a}_{\mathrm{i}} \mathrm{y}_{1}^{\mathrm{i}}+\mathrm{b}_{\mathrm{i}} \mathrm{y}_{2}^{\mathrm{i}}\right)=\mathrm{F}\left(\mathrm{y}_{1}, \mathrm{y}_{2}, \mathrm{y}_{3}, \mathrm{y}_{4}\right)
$$

then we arrive at the stochastic differential equation in the form:

$$
\begin{aligned}
& \text { for symmetric movements: } \\
& \mathrm{y}_{1}=\mathrm{F}_{2}(\mathrm{t}) \\
& \dot{\mathrm{y}}_{1}=\mathrm{y}_{2} \\
& \dot{\mathrm{y}}_{2}=\mathrm{y}_{3} \\
& \dot{\mathrm{y}}_{3}=-\mathrm{S}_{02}-\mathrm{S}_{12} \mathrm{y}_{1}-\mathrm{S}_{22} \mathrm{y}_{2}-\mathrm{S}_{32} \mathrm{y}_{3}+\mathrm{W}_{2}(\mathrm{t}) \\
& \mathrm{y}_{4}=\mathrm{F}_{3}(\mathrm{t}) \\
& \dot{\mathrm{y}}_{4}=\mathrm{y}_{5} \\
& \dot{\mathrm{y}}_{5}=\mathrm{y}_{6} \\
& \dot{\mathrm{y}}_{6}=-\mathrm{S}_{03}-\mathrm{S}_{13} \mathrm{y}_{1}-\mathrm{S}_{23} \mathrm{y}_{2}-\mathrm{S}_{33} \mathrm{y}_{3}+\mathrm{W}_{3}(\mathrm{t})
\end{aligned}
$$

* for antisymmetric movements:

$$
\begin{aligned}
& \mathrm{y}_{1}=\mathrm{F}_{4}(\mathrm{t}) \\
& \dot{\mathrm{y}}_{1}=\mathrm{y}_{2} \\
& \dot{\mathrm{y}}_{2}=\mathrm{y}_{3} \\
& \dot{\mathrm{y}}_{3}=-\mathrm{S}_{04}-\mathrm{S}_{14} \mathrm{y}_{1}-\mathrm{S}_{24} \mathrm{y}_{2}-\mathrm{S}_{34} \mathrm{y}_{3}+\mathrm{W}_{4}(\mathrm{t}) \\
& \mathrm{y}_{4}=\mathrm{F}_{5}(\mathrm{t}) \\
& \dot{\mathrm{y}}_{4}=\mathrm{y}_{5} \\
& \dot{\mathrm{y}}_{5}=\mathrm{y}_{6} \\
& \dot{\mathrm{y}}_{6}=-\mathrm{S}_{05}-\mathrm{S}_{15} \mathrm{y}_{1}-\mathrm{S}_{25} \mathrm{y}_{2}-\mathrm{S}_{35} \mathrm{y}_{3}+\mathrm{W}_{5}(\mathrm{t}) \\
& \mathrm{y}_{7}=\mathrm{F}_{6}(\mathrm{t}) \\
& \dot{\mathrm{y}}_{7}=\mathrm{y}_{8} \\
& \dot{\mathrm{y}}_{8}=\mathrm{y}_{9} \\
& \dot{\mathrm{y}}_{9}=-\mathrm{S}_{06}-\mathrm{S}_{16} \mathrm{y}_{1}-\mathrm{S}_{26} \mathrm{y}_{2}-\mathrm{S}_{36} \mathrm{y}_{3}+\mathrm{W}_{6}(\mathrm{t})
\end{aligned}
$$

where:

W - "white noise"

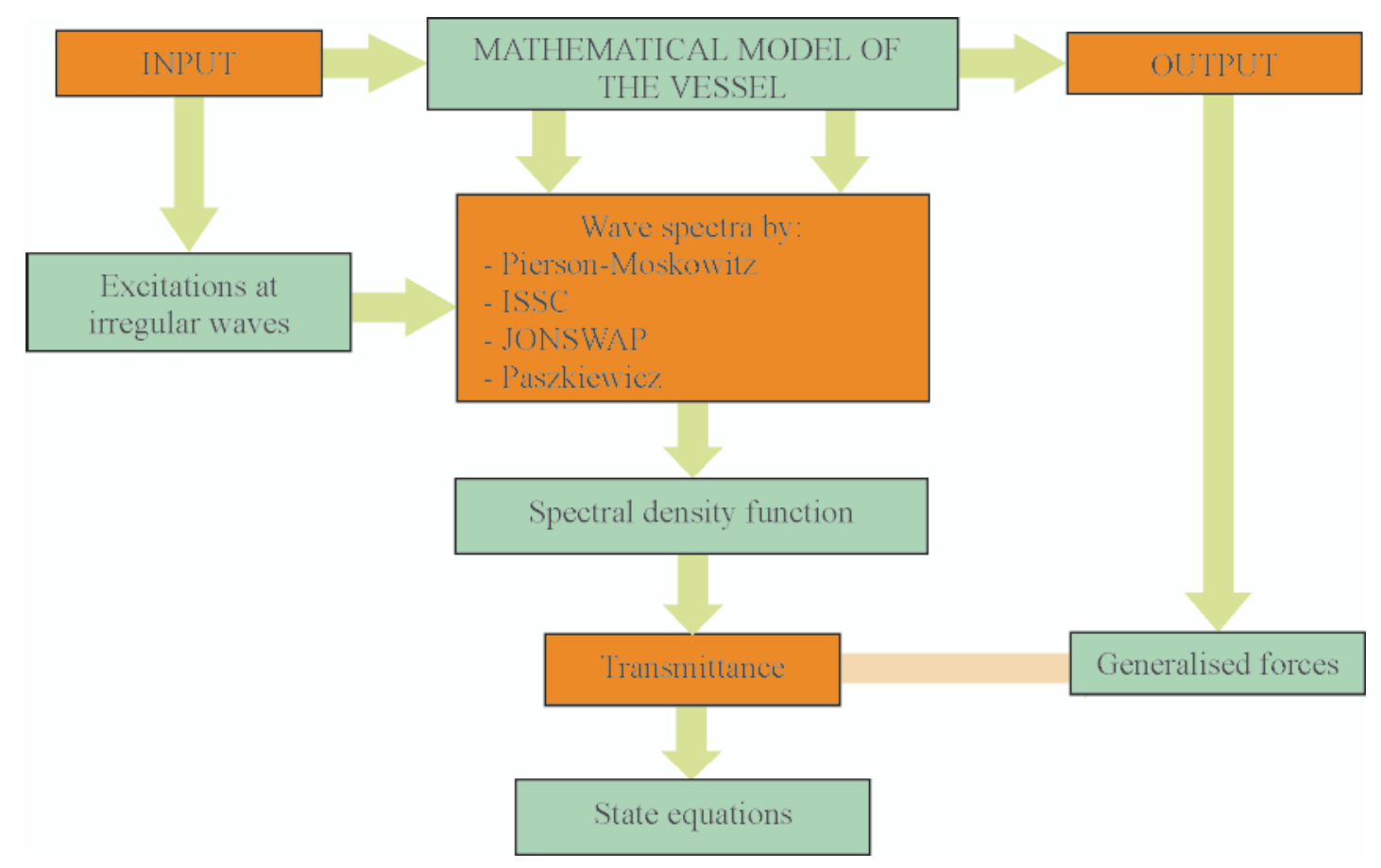

Fig. 3. Schematic procedure for determining the exciting forces in the mathematical model 
$S_{i}$ - coefficients of linear filters (determined from the correlation function of the excitation, or from its spectral density).

Using relevant linear filters we replace the "white noise" process, for which the spectral density is constant, with the densities corresponding to different wave spectra.

\section{Deriving the set of state equations}

State equations are one of possible ways in which the mathematical model of a dynamic system can be represented. The system output for time $t_{n}$ depends not only on the system input at time $t_{n}$ but also on past inputs at all times $t_{i}\left(t_{i}<t_{n}\right)$.

An alternative method of describing the dynamic system to that represented by the state equations is the transmittance, which assumes that the initial state is equal to zero.

The operator transmittance, also referred to as the transfer function $G(s)$, is the ratio of the Laplace transforms of the system's output and input signals when the initial conditions are equal to zero. The transmittance describes general stationary characteristics of the linear system with one input and one output, irrelevant of the type of excitation. For systems described by linear differential equations with constant coefficients, the transmittance is a rational function of the complex variable s and can be presented using the ratio of two polynomials (10).

When deriving the set of state equations we adopt the following assumptions:

is the resultant movement of the object on an irregular wave is the superposition of its movements on regular waves

is only the head sea effect is taken into account, and it is the source of the following movements: $\eta_{1}$ - surge, $\eta_{3}$ - heave and $\eta_{5}$ - pitch.

With the use of the equation (1), the wave-excited motion of an object is given by the following state equation:

$$
\mathrm{I} \ddot{\eta}+\mathrm{B} \dot{\eta}+\mathrm{C} \eta=\mathrm{F}_{\mathrm{w}}
$$

where :

$$
\left.\begin{array}{l}
\dot{\mathrm{P}}=\mathrm{Q} \\
\dot{\mathrm{Q}}=-\mathrm{I}^{-1} \mathrm{~B} \dot{\eta}-\mathrm{I}^{-1} \mathrm{C} \eta+\mathrm{I}^{-1} \mathrm{~F}_{\mathrm{w}}
\end{array}\right\}
$$

I, B, C-matrices $3 \times 3$

$$
\mathrm{P}=\left\{\begin{array}{l}
\eta_{1} \\
\eta_{3} \\
\eta_{5}
\end{array}\right\}, Q=\left\{\begin{array}{l}
\dot{\eta}_{1} \\
\dot{\eta}_{3} \\
\dot{\eta}_{5}
\end{array}\right\}, \mathrm{F}_{\mathrm{w}}=\left\{\begin{array}{l}
\mathrm{F}_{1} \\
\mathrm{~F}_{3} \\
\mathrm{~F}_{5}
\end{array}\right\}
$$

is it is assumed that the response, in the form of generalised forces $\mathrm{Fi}=(\mathrm{i}=1,3,5)$, to the excitation coming from the wave of the height $\xi(t)$ can be approximated by the system whose transmittance has the form:

$$
\frac{F(s)}{\xi(s)}=\frac{b_{0} s^{2}+b_{1} s+b_{2}}{s^{2}+a_{1} s+a_{2}}
$$

where:

$$
\begin{aligned}
& F\left(F_{1}, F_{3}, F_{5}\right), \\
& b_{0}\left(b_{01}, b_{03}, b_{05}\right), b_{1}\left(b_{11}, b_{13}, b_{15}\right), b_{2}\left(b_{21}, b_{23}, b_{25}\right), \\
& a_{1}\left(a_{11}, a_{13}, a_{15}\right), a_{2}\left(a_{21}, a_{23}, a_{25}\right) .
\end{aligned}
$$

The relation (10) can be written using the following set of state equations:

$$
\begin{aligned}
& \mathrm{f}_{1}=\mathrm{F}-\mathrm{h}_{0} \xi \\
& \mathrm{f}_{2}=\dot{\mathrm{F}}-\mathrm{h}_{0} \dot{\xi}-\mathrm{h}_{1} \xi
\end{aligned}
$$

$$
\left.\begin{array}{l}
\dot{\mathrm{f}}_{1}=\mathrm{f}_{2}+\mathrm{h}_{1} \xi \\
\dot{\mathrm{f}}_{2}=-\mathrm{a}_{2} \mathrm{f}_{1}-\mathrm{a}_{1} \mathrm{f}_{2}+\mathrm{h}_{2} \xi
\end{array}\right\}
$$

where:

$\mathrm{h}_{0}, \mathrm{~h}_{1}, \mathrm{~h}_{2}$ - constants defined by coefficients in equation (10)

$\mathrm{f}_{1}\left(\mathrm{f}_{11}, \mathrm{f}_{13}, \mathrm{f}_{15}\right), \mathrm{f}_{2}\left(\mathrm{f}_{21}, \mathrm{f}_{23}, \mathrm{f}_{25}\right)$,

$\mathrm{h}_{0}\left(\mathrm{~h}_{01}, \mathrm{~h}_{03}, \mathrm{~h}_{05}\right), \mathrm{h}_{1}\left(\mathrm{~h}_{11}, \mathrm{~h}_{13}, \mathrm{~h}_{15}\right), \mathrm{h}_{2}\left(\mathrm{~h}_{21}, \mathrm{~h}_{23}, \mathrm{~h}_{25}\right)$.

To obtain the random process of wave height $\xi(\mathrm{t})$ (irregular wave), well-known energy spectra (wave spectra) of the wave which approaches the object are to be used:

$\phi_{\xi \xi}(\omega)=\left\{\begin{array}{l}- \text { Pierson Moskowitz spectrum, for instance } \\ - \text { ISSC spectrum, for instance }\end{array}\right.$

We approximate the selected spectrum using the spectral density function in the form:

$$
g(\omega)=\frac{c \omega^{2}}{\omega^{4}-2 v \omega_{0}^{2} \omega^{2}+\omega_{0}^{4}}
$$

Then, we introduce the shape filter making use of the following assumptions:

$\Rightarrow$ In the two spectra (13) and (14) the maxima take place at the same frequency and are the same in magnitude

$\Rightarrow \int_{0}^{\infty} \phi_{\xi \xi}(\omega) \mathrm{d} \omega=\int_{0}^{\infty} g(\omega) \mathrm{d} \omega$

$\Rightarrow$ The wave height processes are generated by the transmittance G(s). If the so-called "white noise" is at input, then it is a so-called shape filter. Transmittance G(s) is given by the formula [9]:

$$
\mathrm{G}(\mathrm{s})=\frac{\mathrm{a}_{0} \mathrm{~s}}{\mathrm{~s}^{2}+\mathrm{a}_{1} \mathrm{~s}+\mathrm{a}_{2}}
$$

The relation (15) corresponds to the following set of state equations:

$$
\left.\begin{array}{c}
\mathrm{g}_{1}=\xi \\
\mathrm{g}_{2}=\dot{\xi}-\mathrm{a}_{0} \mathrm{~W}
\end{array}\right\}
$$

where:

W - "white noise".

\section{CONCLUSIONS}

In the stochastic process of undulation, linear filters can be applied for irregular undulation in long time intervals. These filters are to be worked out in such a way that the parametric excitations generated by the wave can be described using basic spectra of Pierson-Moskowitz, ISSC, Jonswap, StriekałowMassel or Paszkiewicz type.

The most frequently used wave spectra (in the dimensionless form - after parametrisation) are given by the following formula:

$$
\mathrm{F}=\frac{\mathrm{S}_{\eta}(\omega)}{\mathrm{h}_{1 / 3}^{2} \mathrm{~T}_{\mathrm{k}}}
$$

where:

$\mathrm{S}_{\eta}(\omega)$ - one-dimensional spectral density function

$\mathrm{T}_{\mathrm{k}}^{\eta} \quad$ time periods

$\mathrm{h}$ - wave height. 
An important stage in stochastic undulation modelling is selecting the parameters which describe the phenomenon and finding unique relations between wind parameters and undulation parameters.

The main conclusions which can be formulated based on the data presented in the article are the following:

For both the wave spectrum, and the spectral density function, the maximum takes place at the same frequency and is the same in magnitude.

The values of the integrals in the infinite interval for the wave spectrum and the spectral density function are equal to each other.

After deriving the set of state equations, the further goal will be working out and solving Itô equations for symmetric movements.

$\mathrm{O}$ In order to obtain the final set of equations we have to determine coefficients in the equation $\mathrm{X}=\widetilde{\mathrm{A} X}+\widetilde{\mathrm{BW}}$, which will be done as part of future continuation of the subject matter presented here.

\section{BIBLIOGRAPHY}

1. Davis M.R.: Holloway D.S. and Watson N.L., Dynamic wave loads on a high speed catamaran ferry fitted with $t$-foils and stern tabs. Transactions of the Royal Institution of Naval Architects, International Journal of Maritime Engineering, Vol.148, Part A1, 1-16, 2006

2. Gichman I.I.: Skorochod A.W., Introduction to the theory of stochastic processes (in Polish). Warsaw 1968

3. Gutowski R.: Ordinary differential equations (in Polish), Warsaw 1971
4. Kang D., Hasegawa K., Prediction method of hydrodynamic forces acting on the hull of a blunt-body ship in the even keel condition. Journal of Marine Science and Technology, Vol. 12, Number 1, 1-14, 2007.

5. Królicka A.: Stochastic approach to the dynamics of a linear floating object. Marine Technology Transactions-Vol.17, pp.121130, Gdańsk 2006.

6. Rumianowski A.: Studying the dynamics of selected marine floating objects (in Polish). Gdańsk 2003

7. Rumianowski A.: Stochastic approach to the dynamics of marine floating objects. Marine Technology TransactionsVol.17, pp. 155-165, Gdańsk 2006

8. Sobczyk K.: Stochastic differential equations (in Polish). Warsaw 1996

9. Sobczyk K.: Spencer Jr.,B.F., Stochastic models of material fatigue (in Polish). Wydawnictwa Naukowo-Techniczne, Warsaw 1996

10.Trębacki K., Królicka A.: External loads for multihull watercraft. Vibrations in physical systems, Vol.XXIII-pp 371376, Poznań 2008.

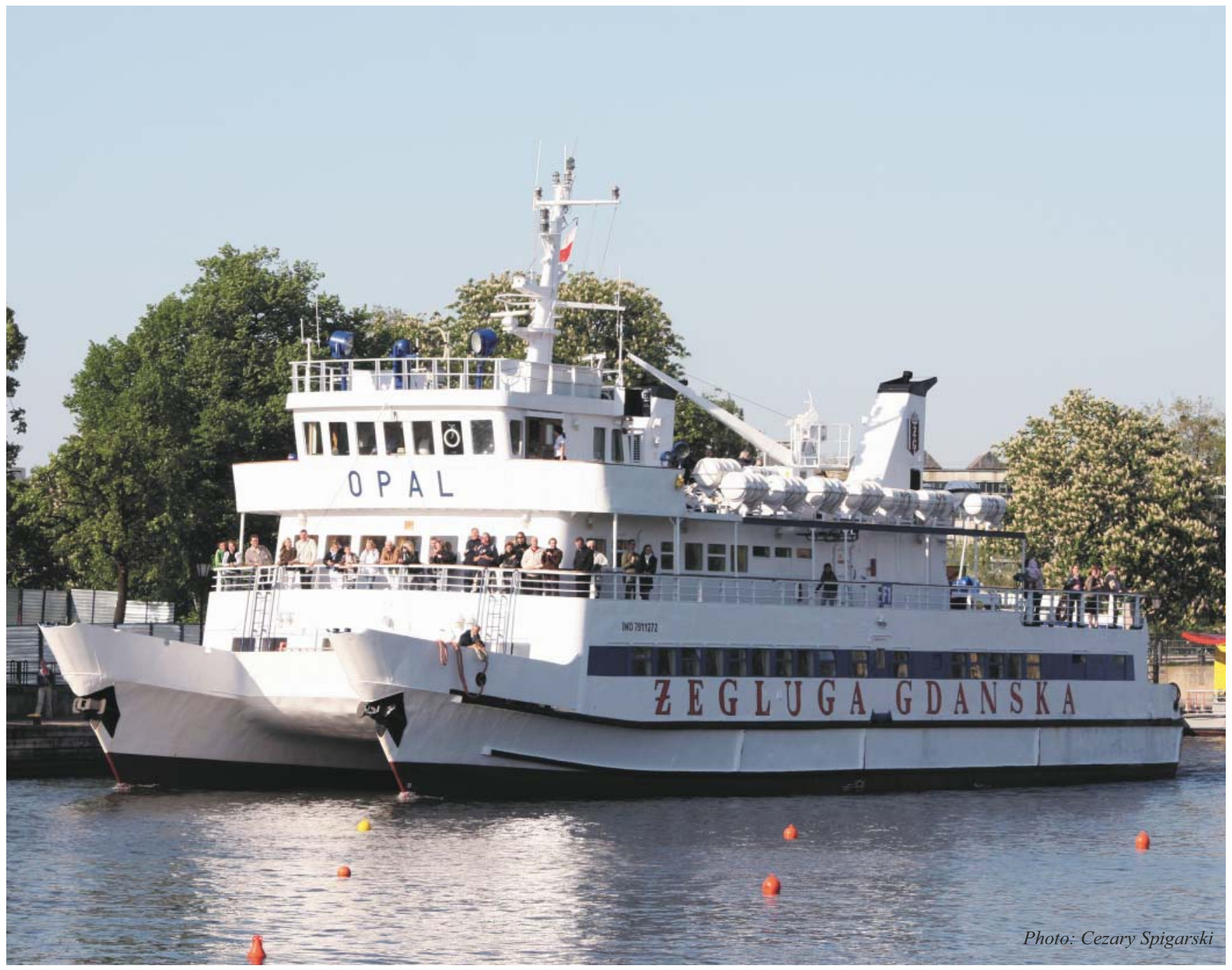

\section{CONTACT WITH THE AUTHOR}

Agnieszka Królicka, Ms. C.

Faculty of Ocean Engineering and Ship Technology,

Gdańsk University of Technology Narutowicza 11/12

80-952 Gdańsk, POLAND

e-mail : krag@pg.gda.pl phone:(058) 347-11-46 